\title{
Metastasis of breast carcinoma to the paranasal sinus: report of two cases and systematic review of literature*
}

\author{
Sietze Reitsma', Paul J. Schuil \\ Department of Otorhinolaryngology, Amsterdam Medical Center, Amsterdam, the Netherlands \\ 2 Department of Otorhinolaryngology, Elkerliek Ziekenhuis, Helmond, the Netherlands
}

Rhinology Online, Vol 1: 3-8, 2018

http://doi.org/10.4193/RHINOL/18.001

*Received for publication:

January 17, 2018

Accepted: February 24, 2018

Published: March 5, 2018

Updated: April 13, 2018

\begin{abstract}
Background: Metastasis of breast carcinoma to the paranasal sinus is rare. There is hardly any accumulated data to guide therapy and counseling.

Methods and results: We report two cases and performed a systematic review. To date, 40 other cases have been reported since 1939 with a median survival of only 6 months after first presentation. The median time between diagnosis of the primary tumor and discovery of the paranasal metastasis was 33 months. Only nine cases of solitary paranasal sinus metastasis could be identified, having the same poor prognosis. Overall, no indicators could be found for a better prognosis, not even the type of treatment (if any).

Conclusions: Paranasal metastases of breast carcinoma are rare but lethal. Treatment should be aimed at palliation only. Extra care should be taken when patients with a history of breast cancer present with complaints of headaches, facial pain, visual impairment or (unilateral) nasal obstruction.
\end{abstract}

Key words: breast carcinoma, paranasal sinus, metastasis, anterior skull base, systematic review

\section{Introduction}

The most common cause of cancer-related death among women worldwide is breast cancer ${ }^{(1)}$. In Western countries, $6 \%$ of the affected women present with metastasized disease at time of diagnosis ${ }^{(2)}$. Metastases of primary breast carcinoma usually home to bone, lungs, liver or brain. We recently encountered two rare, but comparable cases of breast cancer metastases to the paranasal sinus. After the first case report on this subject by Robin in $1939^{(3)}$ about forty similar cases have been described. However, almost no overall data have yet been collected describing survival rates or treatment options. We therefore performed a systematic review of all cases of breast cancer metastasis to the paranasal sinus in addition to reporting our two cases, aiming to find guidance for therapy and counseling.

The paranasal sinus are a rare but known location for metasta- ses. Previous studies indicate that $8 \%$ originates from primary breast cancer. Other, more prevalent metastases in the paranasal sinus are from renal cell carcinoma (40\%) and bronchogenic carcinoma (9\%); also thyroid gland tumors (8\%) and prostate cancer (7\%) can metastasize to the paranasal sinus ${ }^{(4)}$. Clinically, these metastases usually present with unilateral nasal obstruction, epistaxis (especially true for renal cell carcinoma), and symptoms suggesting orbital involvement. Upon imaging, the suspicion of a malignancy is raised when these mostly unilateral processes exhibit destruction of bony boundaries and invasion of surrounding tissues (orbit, anterior skull base, skin, palate, cavernous sinus, etc.).

\section{Case I}

A 79-year-old lady presented with right-sided complaints of nasal obstruction, purulent rhinorrhea and post nasal drip. She 


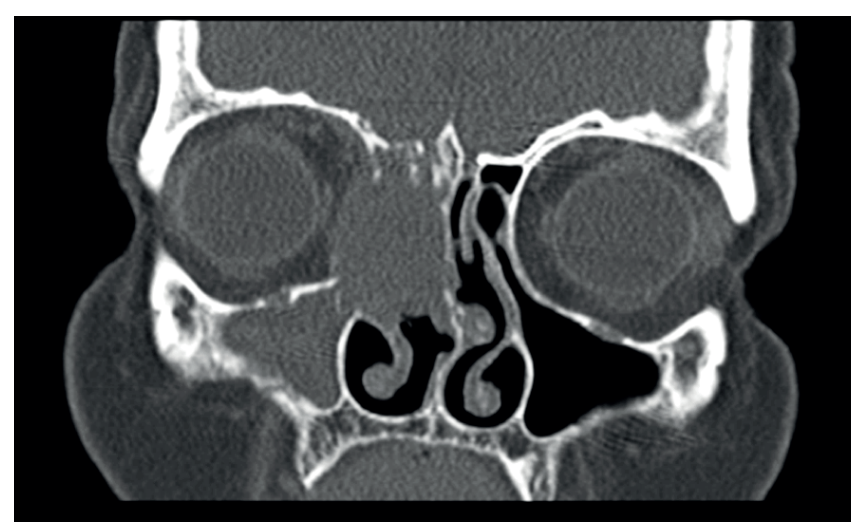

Figure 1. Coronal section of CT scan showing a mass in the right ethmoid sinus with involvement of the orbit and anterior skull base.

also experienced headaches located near the right frontal sinus. She had used several antibiotics without marked effect. Lately, she had noticed a swelling of the nasal dorsum. Her general practitioner suspected an abscess and referred her to our Ear, Nose and Throat department.

Four years earlier she was diagnosed with right-sided breast carcinoma. She underwent a lumpectomy with axillary lymph node clearance. Histological examination of the specimen revealed a pT2N1A invasive lobular carcinoma, both estrogen and progesterone receptor (ER and PR) positive. The surgical procedure was followed by radiotherapy and hormonal therapy. Due to side-effects the hormonal therapy (tamoxifene) was stopped after 2,5 years.

Clinical examination showed asymmetry of the nasal dorsum to the right, without signs of infection. Nasal endoscopy revealed a granulative mass and pus in the right middle meatus. Her eye movements and visual acuity were normal. Computed tomography and magnetic resonance imaging of the head and neck region demonstrated a solitary mass in the right ethmoid sinus expanding into the right orbit and into the nasal cavity (Figure 1). The anterior skull base was also infiltrated with signs of intracranial growth. A biopsy confirmed that the mass was a metastasis of the previously diagnosed breast carcinoma. She was treated with radiotherapy. A year after her first presentation, the metastasis had grown even further and palliative chemotherapy (capecitabine) was started. As the metastasis did not respond, palliative radiotherapy was started. She lived another 1,5 year and died 4,5 years after her first presentation to our clinic.

\section{Case 2}

A 79-year-old lady visited our outpatient clinic for left-sided nasal obstruction since two months, accompanied by a gradually deteriorating deviation of the nose. During the same time, she developed a progressive left-sided facial nerve palsy. There were no complaints of rhinosinusitis or discharge.

She had a medical history of Parkinson's disease and a breast

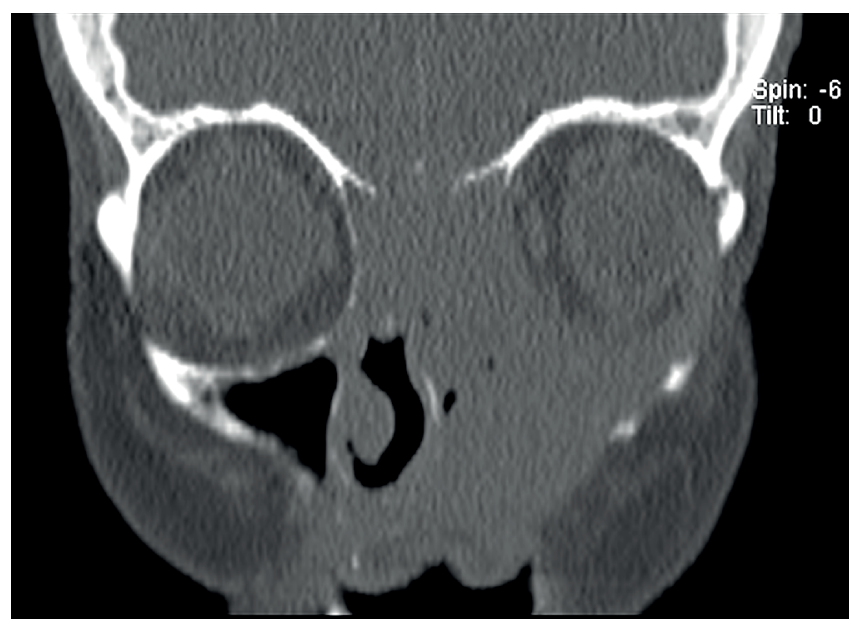

Figure 2. Coronal section of $\mathrm{CT}$ scan showing a large mass growing from the left ethmoid into the maxillary sinus, lamina papyracea and orbital floor, extending laterally into the zygoma and caudally into the hard palate. The anterior skull base cannot be delineated accurately.

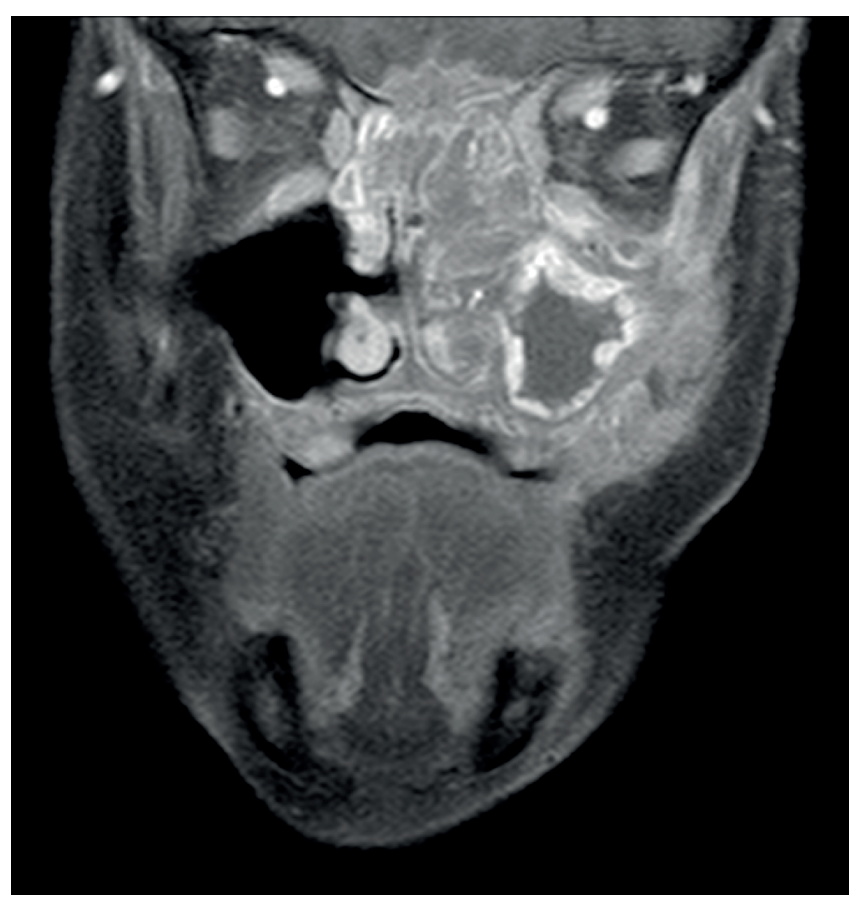

Figure 3. Coronal section of MRI scan somewhat posterior to Figure 2. Infiltration of the skull base and the contralateral ethmoid can clearly be seen, as well as extension to the skin over the zygoma and left cheek.

carcinoma treated three years before with surgery (mastectomy, with axillary lymph node clearance), radiotherapy and hormonal therapy (letrozole). Histological examination of the specimen revealed an invasive ductal carcinoma, ER and PR receptor positive. Staging of the tumor was pT2N2aMx.

Clinical examination revealed a facial nerve palsy HouseBrackmann grade V/VI. The nasal dorsum deviated to the right due to a subcutaneous tumor located at the transition of the left zygoma to the nasal dorsum. Nasal endoscopy showed a 
granulative mass filling the nasal cavity on the left side, from which a biopsy was taken. Computed tomography and magnetic resonance imaging scans described a large mass infiltrating both ethmoidal sinus, the left nasal cavity, the left orbit, the skull base, the cavernous sinus and even the left lateral skull base (Figures 2 and 3). The facial nerve, however, was not affected by the process. Near the zygoma, infiltration of the skin was observed. Multiple pathologically enlarged cervical lymph nodes were found bilaterally.

The biopsy demonstrated a metastasis of her previous breast carcinoma. The patient had no wish for further diagnostics or treatment, and refused palliative hormonal therapy. She died six months after her first visit to our department.

\section{Materials and methods}

Pubmed en Embase medical libraries were queried on August 31st, 2017 for MESH terms 'breast neoplasm' combined with 'paranasal sinus' or 'paranasal neoplasm' (Pubmed), or 'paranasal sinus.mp' and 'breast cancer or breast carcinoma.mp' (Embase). Titles and abstracts were screened (see below for exclusion criteria). All included articles were hand-searched for additional references. This way, 38 relevant papers were identified containing 40 cases (Figure 4 and Table 1). Full text was retrieved in 35 of them (92\%).

Exclusion criteria were: language other than English, Italian, Spanish, French, German, or Dutch; papers describing primary tumors in the paranasal sinus, or metastases to the nasal cavity only; cases involving metastases to other related regions (e.g. cavernous sinus) with expansion into the paranasal sinus. Variables collected from the case reports were sex, age at time of diagnosis, presenting signs and symptoms, time interval between diagnosis of the primary and the metastasis, survival after diagnosis of metastasis, treatment for the primary tumor and for the metastasis (if any), other concurrent metastases, type of primary tumor, location of the metastasis (one or more of: maxillary sinus, ethmoid sinus, frontal sinus, sphenoid sinus; and which side) and expansion into adjacent structures (e.g. orbit, skull base, cavernous sinus). Data was collected from 40 cases including the two from the current report. Because of missing data and/or skewed distribution most data are presented as medians with interquartile ranges and the number of available cases for the given outcome variable. For the presentation of the cases in this report, oral consent was retrieved.

\section{Results}

Through a systematic literature search, 40 other cases of breast cancer metastasis to the paranasal sinus were found (Table 1). Interestingly, there are two very rare cases in literature regarding breast cancer metastasis to the paranasal sinus in a man ${ }^{(5,6)}$. The mean age at the time of discovery of the paranasal metastasis was 60 years, ranging from $34-83(n=39)$. Presenting signs and
Table 1. Reports of breast cancer metastases to the paranasal sinus.

\begin{tabular}{|c|c|c|}
\hline First Author & Year & Remarks \\
\hline Robin ${ }^{(3)}$ & 1939 & \\
\hline Archilei $^{(13)}$ & 1959 & No full text available \\
\hline Garrett ${ }^{(14)}$ & 1959 & \\
\hline Nahum ${ }^{(15)}$ & 1963 & \\
\hline Bernstein $^{(16)}$ & 1966 & \\
\hline Sossi ${ }^{(17)}$ & 1967 & \\
\hline Myers ${ }^{(18)}$ & 1968 & \\
\hline Jortay ${ }^{(19)}$ & 1971 & 2 cases \\
\hline Robinson ${ }^{(20)}$ & 1973 & \\
\hline Barrs (21) & 1979 & \\
\hline Nelson ${ }^{(22)}$ & 1990 & \\
\hline Austin (23) & 1995 & \\
\hline García Triguero ${ }^{(24)}$ & 1998 & No full text available \\
\hline Pignataro ${ }^{(25)}$ & 2001 & \\
\hline Monserez ${ }^{(10)}$ & 2001 & \\
\hline Pitkäranta (26) & 2001 & \\
\hline Hiromura $^{(27)}$ & 2003 & \\
\hline Belkheiri ${ }^{(28)}$ & 2003 & No full text available \\
\hline Asproudis (29) & 2004 & \\
\hline Marchioni ${ }^{(30)}$ & 2004 & \\
\hline Busl (31) & 2008 & \\
\hline Fyrmpas ${ }^{(32)}$ & 2008 & \\
\hline Huang ${ }^{(33)}$ & 2008 & 2 cases \\
\hline Darouassi ${ }^{(5)}$ & 2010 & Male patient \\
\hline Cheng ${ }^{(34)}$ & 2010 & \\
\hline Reimann ${ }^{(35)}$ & 2011 & \\
\hline Azarpira ${ }^{(36)}$ & 2011 & \\
\hline Davey ${ }^{(12)}$ & 2012 & \\
\hline Walker ${ }^{(37)}$ & 2013 & \\
\hline Atasoy ${ }^{(38)}$ & 2013 & \\
\hline Johnston (39) & 2013 & \\
\hline Imre ${ }^{(40)}$ & 2013 & \\
\hline Pittoni ${ }^{(41)}$ & 2014 & \\
\hline Leone ${ }^{(42)}$ & 2014 & \\
\hline Namad ${ }^{(43)}$ & 2014 & \\
\hline Chafale ${ }^{(44)}$ & 2015 & \\
\hline Roberts ${ }^{(45)}$ & 2015 & \\
\hline Agrawal (6) & 2016 & Male patient \\
\hline
\end{tabular}

symptoms were specified in 39 cases. Most common complaints were headache/facial pain, visual complaints, and swelling of the face or eyelids $(62,44$, and $28 \%$, respectively). Nasal obstruction and epistaxis were reported in the minority of cases (26 and $8 \%$, respectively). 


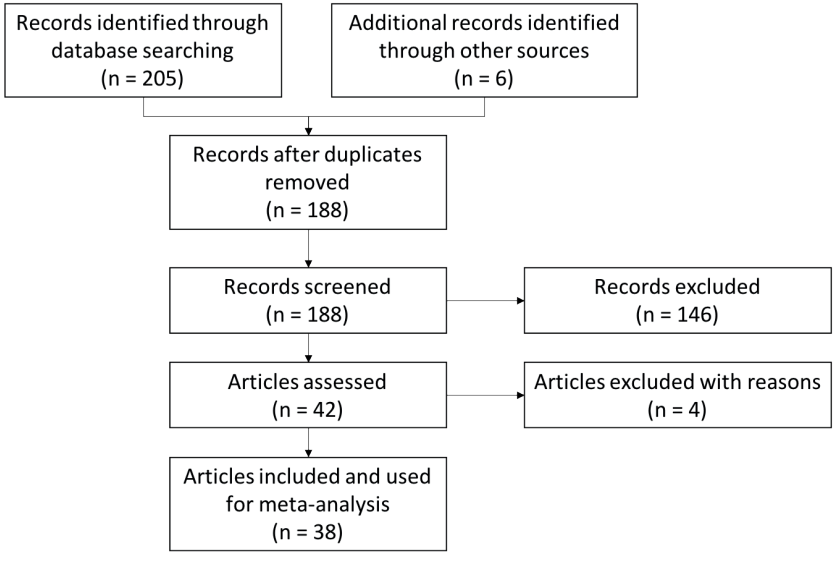

Figure 4. Results of the systematic literature review.

There was a wide variety in times between diagnosis of the primary and the metastasis. In 5 cases the metastasis to the paranasal sinus led to the discovery of the primary tumor. In other cases, several years passed between the treatment of the primary and the discovery of the metastasis. In one case, the metastasis to the paranasal sinus was only discovered during autopsy. Overall, the median time lapse was 33 months (17-72; $\mathrm{n}=38$ ). Most cases of paranasal metastasis of breast cancer had metastases in other sites as well; in only 9 cases $(21,4 \%)$ no other sites were found. In three of these, other distant metastases developed or became apparent within months after first presentation and diagnostic workup. In 9 other cases $(21,4 \%)$ the presence or absence of other metastases was not described. As such, at least $57 \%$ had concurrent metastases elsewhere.

The exact paranasal location of breast cancer metastases varied. In case of a single site metastasis ( $n=26)$, the maxillary $(23 \%)$ and the ethmoid (23\%) sinuses were most often involved, followed by sphenoid (15\%) and frontal (5\%). In $38 \%$ of all cases, the metastasis covered multiple sinus. The more recent reports tend to describe metastasis location in more detail based on availability of imaging modalities such as CT and MRI. As such, coverage of multiple sinus (e.g. maxillary and ethmoid) was related to year of publication.

Expansion into adjacent structures was present in 21 cases (64\%; $\mathrm{n}=33$ ) including orbital invasion, destruction of the anterior skull base, cavernous sinus involvement and induration of the facial skin. In 9 cases, the presence or absence of such expansion was not described; most of these reports were written before 1980 .

In general, discovery of breast cancer metastasis to the paranasal sinus has a poor prognosis. The median survival after the first presentation was 6 months (2-13,5; $n=29 ; 6$ cases were lost to follow-up but had a survival of 15 months or more, and were included to determine the median survival). The majority of cases (64\%) died within eight months after the diagnosis. None of the patients was reported alive five years after the diagnosis. Overall, the collected data was too sparse for advanced statistical modeling. Simple stratification for age, time lapse between diagnosis of primary and of paranasal metastasis, localization of the metastasis, presence of other metastases, type of primary tumor, or treatment for the primary tumor and for the metastasis (if any) showed no correlation with survival times.

The nine cases with a solitary paranasal breast cancer metastasis underwent varying treatments; one received no treatment; three underwent radiotherapy in curative setting; one received radiotherapy combined with hormonal therapy; two had surgery either combined with radiotherapy or chemotherapy; and two were irradiated in a palliative setting. Survival times were not significantly different from cases with other metastases: median survival for solitary paranasal metastasis was 9 months (429; $n=9$ ). From these low numbers, no clear conclusions could be inferred regarding best treatment options and/or survival times. Still, no major effect of treatment was apparent in cases of solitary paranasal metastasis.

The primary tumor receptor status was (partially) reported in 17 cases. Estrogen receptor was positive in 12 of 17 cases (71\%), progesterone receptor was positive in 10 of 14 cases (71\%), and human epidermal growth factor receptor-2 was positive in 4 of 11 cases (36\%). As such, receptor status of breast cancer metastasizing to the paranasal sinus was in line with overall expression patterns of primary breast cancers ${ }^{(7)}$. Moreover, comparison of survival times between different biological subtypes of the primary tumor (data available in 14 cases) showed no differences.

\section{Discussion}

Metastasis of primary tumors to the paranasal sinuses is a rare event. In 2001, Prescher and Brors reviewed 169 cases, of which only $8 \%$ originated from primary breast cancer ${ }^{(4)}$. From our own extensive literature search, a total of 40 cases were identified, mostly adding more recent case reports to the ones identified by Prescher and Brors.

The two cases we present in the current paper are generally comparable to those already reported. Some interesting points can be made, however. In case I, the survival of almost five years after the discovery of the paranasal metastasis is the longest yet reported. There are no specific clues explaining this long survival. In case II, there was a concurrent facial nerve palsy on the left side, which has not been reported in other cases. This could not be explained by direct invasion as the metastasis did not come into contact with the facial nerve. Possibly, the facial palsy was a paraneoplastic phenomenon. 
Three different hypotheses exist on the exact mechanism of metastasis to the paranasal sinus. The most prevalent hypothesis states that the tumor cells migrate via the vertebral veins and jugular venous system (route of Batson) ${ }^{(8)}$. Through these valveless veins, metastasic cells could home directly to the paranasal sinus by retrograde flow during moments of increased pressure (as Batson showed during Valsalva manoeuvre) ${ }^{(9)}$. By others, it is proposed to be a hematogenous pathway, possibly seeding from occult pulmonary (micro)metastases ${ }^{(10)}$. The third hypothesis is based on symmetrical bilateral ethmoidal metastasis in some cases suggesting leptomeningeal and transcribrosal spread of tumor ${ }^{(10)}$.

None of the reported cases survived paranasal metastasis of breast carcinoma, not even when this was a solitary metastasis. The majority of patients died within eight months upon diagnosis. Early diagnosis did not lead to improved survival, nor did any form of treatment result in significantly raised survival times. None of the patients is reported alive five years later. Furthermore, paranasal metastasis is often a sign of more widespread disease. On the other hand, numbers are low and variation in patient characteristics wide. Still, we feel that treatment should be aimed at palliation and quality of life. As such, extensive and disfiguring surgical procedures should be avoided. Should there be an indication for surgery, an endoscopic approach is favorable ${ }^{(11)}$. Suggestions to treat a solitary metastasis as a primary tumor do not find any evidence in the reviewed cases ${ }^{(12)}$.

\section{Conclusion}

To date, forty cases of breast cancer metastasis to the paranasal sinus have been reported. Although we currently report the longest survival (almost five years after diagnosis), prognosis is very poor. Treatment should be aimed at palliation and quality of life. Obviously, care should be taken when encountering a patient with a history of breast cancer complaining of headaches, facial pain, visual impairment or (unilateral) nasal obstruction.

\section{Authorship contribution}

PJ Schuil was involved in the clinical work up of our cases and reading / commenting on the manuscript. S Reitsma performed the systematic review and wrote the manuscript.

\section{Conflict of interest}

The authors have no conflicts of interest to declare.

\section{References}

1. Anderson BO, Yip $\mathrm{CH}$, Smith RA, et al. Guideline implementation for breast healthcare in low-income and middleincome countries: overview of the Breast Health Global Initiative Global Summit 2007. Cancer 2008; 113:2221-2243.

2. Sant M, Allemani C, Berrino F, et al. Breast carcinoma survival in Europe and the United States. Cancer 2004; 100:715-722.

3. Robin. Malignant disease of the maxilla with special reference to carcinoma of the antrum. Guy's Hosp Rep 1939; 89:301-329.

4. Prescher A, Brors D. [Metastases to the paranasal sinuses: case report and review of the literature]. Laryngorhinootologie 2001; 80:583-594.

5. Darouassi Y, Fetohi M, Touiheme N, Ichou M, Abrouq A, Azendour B. [Nasosinusal metastasis of a breast cancer in a man]. Presse Med 2010; 39:1340-1342.

6. Agrawal S, Jayant K. Breast Cancer with Metastasis to the Nasopharynx and Paranasal Sinuses. Breast J 2016; 22:476-477.

7. Gerratana L, Fanotto V, Bonotto $M$, et al. Pattern of metastasis and outcome in patients with breast cancer. Clin Exp Metastasis 2015; 32:125-133.

8. Batson OV. The Function of the Vertebral Veins and Their Role in the Spread of Metastases. Ann Surg 1940; 112:138-149.

9. Batson OV. The Valsalva maneuver and the vertebral vein system. Angiology 1960; 11:443-447.

10. Monserez D, Vlaminck S, Kuhweide R, Casselman J. Symmetrical ethmoidal metastases from ductal carcinoma of the breast, suggesting transcribrosal spread. Acta Otorhinolaryngol Belg 2001; 55:251-257.

11. Lund VJ, Wei WI. Endoscopic surgery for malignant sinonasal tumours: an eighteen year experience. Rhinology. 2015;53(3):20411.

12. Davey S, Baer S. A rare case of breast cancer metastasising to the nasopharynx and paranasal sinuses. Int J Surg Case Rep 2012; 3:460-462.

13. Archilei G. [Orbito-paranasal metastases of breast carcinoma]. Boll Mal Orecch Gola Naso 1959; 77:218-229.

14. Garrett MJ. Metastatic tumours of the paranasal sinuses simulating primary growths. J Fac Radiol 1959; 10:151-155.

15. Nahum AM, Bailey BJ. Malignant Tumors Metastatic to the Paranasal Sinuses: Case Report and Review of the Literature. Laryngoscope 1963; 73:942-953.

16. Bernstein JM, Montgomery WW, Balogh K, Jr. Metastatic tumors to the maxilla, nose, and paranasal sinuses. Laryngoscope 1966; 76:621-650.

17. Sossi G. [Clinical and therapeutic observations on a case of secondary tumor of the maxillary sinus]. Minerva Stomatol 1967; 16:30-35.

18. Myers EN. Metastatic carcinoma of the breast occurring in the frontal sinus. J Laryngo Otol 1968; 82:485-487.

19. Jortay AM. Metastatic tumors in oral cavity pharynx and paranasal sinuses. Acta Chir Belg 1971; 70:715-728.

20. Robinson D. Antral metastases from carcinoma. J Laryngo Otol 1973; 87:603-609.

21. Barrs DM, MCDonald TJ, Whisnant JP.
Metastatic tumors to the sphenoid sinus. Laryngoscope 1979; 89:1239-1243.

22. Nelson EG, Goldman ME, Hemmati M Metastatic carcinoma of the ethmoid sinus. Otolaryngol Head Neck Surg 1990; 103:120123.

23. Austin JR, Kershiznek MM, McGill D, Austin SG. Breast carcinoma metastatic to paranasal sinuses. Head Neck 1995; 17:161-165.

24. Garcia Triguero D, Molina Quiros C, Sanz Fernandez R. [Ethmoid metastasis of primary breast tumor]. Acta Otorrinolaringol Esp 1998; 49:163-164.

25. Pignataro L, Peri A, Ottaviani F. Breast carcinoma metastatic to the ethmoid sinus: a case report. Tumori 2001; 87:455-457.

26. Pitkaranta A, Markkola A, Malmberg $\mathrm{H}$ Breast cancer metastasis presenting as ethmoiditis. Rhinology 2001; 39:107-108.

27. Hiromura Y, Dejima K, Imamura Y, Wada Y. Breast carcinoma metastatic to the sphenoid sinus: a case report. Otolaryngol Head Neck Surg 2003; 129:756-758.

28. Belkheiri M, Ahmiti F, Khabouze S, et al. Sphenoid sinus metastasis from breast cancer. A rare case report and literature review. [French]. Sein 2003; 13:40-42.

29. Asproudis I, Gorezis S, Charalabopoulos K, Stefaniotou M, Peschos D, Psilas K. Breast carcinoma metastasis to the orbit and paranasal sinuses: a case report. Exp Oncol 2004; 26:246-248.

30. Marchioni D, Monzani D, Rossi G, Rivasi F, Presutti L. Breast carcinoma metastases in paranasal sinuses, a rare occurrence mimicking a primary nasal malignancy. case report. Acta Otorhinolaryngol Ital 2004; 
24:87-91

31. Busl KM, Alcalay RN. A surprising cause of sinusitis. J Neurooncol 2008; 87:295-297.

32. Fyrmpas G, Televantou D, Papageorgiou V, Nofal F, Constantinidis J. Unsuspected breast carcinoma presenting as orbital complication of rhinosinusitis. Eur Arch Otorhinolaryngol 2008; 265:979-982.

33. Huang HH, Fang TJ, Chang PH, Lee TJ. Sinonasal metastatic tumors in Taiwan. Chang Keng I Hsueh 2008; 31:457-462.

34. Cheng CC, Tsou YA, Lin MH, Tseng GC, Tai CJ, Tsai MH. Metastasis of breast cancer to the sphenoid sinus presenting as tolosa-hunt syndrome. Tzu Chi Med J 2010; 22:153-156.

35. Reimann K, Schulze M, Adam P, Wagner W. [Metastasis to the paranasal sinuses from primary breast cancer]. HNO 2011; 59:915917.

36. Azarpira N, Ashraf MJ, Khademi B, Asadi N. Distant metastases to nasal cavities and paranasal sinuses case series. Indian J Otolaryngol Head Neck Surg 2011; 63:349352.

37. Walker DT, Barbur S, Mathew R, Hern J. Sinus involvement in breast cancer: case report. J Laryngol Otol 2013; 127:619-620.

38. Atasoy BM, Cetin IA, Bozkurt SU, Turhal NS. Metastasis to paranasal sinuses and orbita of breast cancer with a rare metachronous tumor of the uterine cervix. J Craniofac Surg 2013; 24:e64-65.

39. Johnston J, George M, Karkos PD, Dwivedi $\mathrm{RC}$, Leong SC. Late metastasis to macroscopically normal paranasal sinuses from breast cancer. ecancermedicalscience 2013; 7.

40. Imre A, Sakarya EU, Imre SS, Gundogan O, Erdogan N, Rezanko T. Orbital apex syndrome as a sign of unsuspected breast carcinoma. J Craniofac Surg 2013; 24:14761478

41. Pittoni P, Di Lascio S, Conti-Beltraminelli M et al. Paranasal sinus metastasis of breast cancer. BMJ Case Rep 2014; 2014.

42. Leone JP, Bhattacharya S, Socinski MA et al. Metastasis of breast carcinoma to the maxillary sinus. Breast J 2014; 20:318-319.

43. Namad T, Benbrahim Z, Najib R, et al Maxillofacial metastasis from breast cancer
Pan Afr Med J 2014; 19:156.

44. Chafale VA, Lahoti SA, Pandit A Gangopadhyay G, Biswas A. Retrobulbar optic neuropathy secondary to isolated sphenoid sinus disease. J Neurosci Rura Pract 2015; 6:238-240

45. Roberts JM, Brook C, Parnes S. Palliative endoscopic surgery for sinonasal metastases: a case report and literature review. Ear Nose Throat J 2015; 94:E24-26.

\section{Sietze Reitsma}

Amsterdam Medical Center

Dept. of Otorhinolaryngology

Meibergdreef 9

1105 AZ Amsterdam

the Netherlands

T: +31-20-566 3789

E: s.reitsma@amc.nl 